\title{
Watching eyes on potential litter can reduce littering: evidence from two field experiments
}

Melissa Bateson, Rebecca Robinson, Tim Abayomi-Cole, Josh Greenlees, Abby O'Connor, Daniel Nettle

Littering constitutes a major societal problem, and any simple intervention that reduces its prevalence would be widely beneficial. In previous research, we have found that displaying images of watching eyes in the environment makes people less likely to litter. Here, we investigate whether the watching eyes images can be transferred onto the potential items of litter themselves. In two field experiments on a university campus, we created an opportunity to litter by attaching leaflets that either did or did not feature an image of watching eyes to parked bicycles. In both experiments, the watching eyes leaflets were substantially less likely to be littered than control leaflets (odds ratios $0.22-0.32$ ). We also found that people were less likely to litter when there other people in the immediate vicinity than when there were not (odds ratios $0.04-0.25$ ) and, in one experiment but not the other, that eye leaflets only reduced littering when there no other people in the immediate vicinity. We suggest that designing cues of observation into packaging could be a simple but fruitful strategy for reducing littering. 
1 Watching eyes on potential litter can reduce littering: evidence from two field

2 experiments

3 Melissa Bateson ${ }^{1}$, Rebecca Robinson², Tim Abayomi-Cole ${ }^{2}$, Joshua Greenlees ${ }^{2}$, Abby

4 O’Connor ${ }^{2}$, Daniel Nettle ${ }^{1 *}$

5 1. Centre for Behaviour and Evolution $\mathcal{E}$ Institute of Neuroscience, Newcastle

$\begin{array}{ll}6 & \text { University, UK } \\ 7 & \text { 2. } \\ \end{array}$

8 * To whom correspondence should be addressed: Henry Wellcome Building, Framlington

9 Place, Newcastle NE4 6EA, UK; daniel.nettle@ncl.ac.uk 


\section{Abstract}

11 Littering constitutes a major societal problem, and any simple intervention that reduces its

12 prevalence would be widely beneficial. In previous research, we have found that displaying

13 images of watching eyes in the environment makes people less likely to litter. Here, we

14 investigate whether the watching eyes images can be transferred onto the potential items of

15 litter themselves. In two field experiments on a university campus, we created an

16 opportunity to litter by attaching leaflets that either did or did not feature an image of

17 watching eyes to parked bicycles. In both experiments, the watching eyes leaflets were

18 substantially less likely to be littered than control leaflets (odds ratios $0.22-0.32$ ). We also

19 found that people were less likely to litter when there other people in the immediate

20 vicinity than when there were not (odds ratios $0.04-0.25$ ) and, in one experiment but not

21 the other, that eye leaflets only reduced littering when there no other people in the

22 immediate vicinity. We suggest that designing cues of observation into packaging could be a

23 simple but fruitful strategy for reducing littering. 


\section{General Introduction}

25 Littering constitutes a major societal problem. Litter is perceived as unsightly and

26 deleterious to quality of life. It can cause health and safety problems as well as contributing

27 to environmental contamination. Moreover, there is evidence that the presence of litter in an

28 environment can increase the prevalence of other social problems such as crime through

29 what has been termed 'the spreading of disorder' (Keizer, Lindenberg \& Steg, 2008).

30 Furthermore, it is well established that 'littering begets littering' (Kraus, Freedman $\mathcal{E}$

31 Whitcup, 1978; Cialdini, Reno \& Kallgren, 1990; Huffman et al., 1995; Keizer, Lindenberg \&

32 Steg, 2008; Schultz et al., 2011; Weaver, 2015). Therefore, any intervention that reduces

33 littering behaviour has the potential to produce large and synergistic benefits.

34 Our recent research on littering is based on the 'watching eyes effect'. This is the finding that 35 placing images of human eyes in participants' environments often causes them to behave in 36 a more prosocial manner than they otherwise would (Haley \& Fessler, 2005; Bateson, Nettle 37 \& Roberts, 2006; Burnham \& Hare, 2007; Keller \& Pfattheicher, 2011; Oda et al., 2011;

38 Nettle et al., 2012; Powell, Roberts \& Nettle, 2012; Baillon, Selim \& van Dolder, 2013; Sparks

$39 \&$ Barclay, 2013). Actions observed by others can have social and reputational

40 consequences, whereas those that go unobserved cannot. Thus, individuals are highly

41 sensitive to cues indicative of observation, and it seems that even subtle (and in the case of

42 artificial eye images, false) cues are in some instances sufficient to modulate behaviour,

43 producing behavioural decisions more likely to meet the approval of others.

44 Three previous studies have investigated whether the watching eyes effect can be used to

45 reduce littering and encourage proper disposal (Ernest-Jones, Nettle \& Bateson, 2011;

46 Francey \& Bergmuller, 2012; Bateson et al., 2013). These studies used wall-mounted images

47 of eyes at locations where individuals had either naturally occurring or experimentally-

48 provided opportunities to litter. All three studies found evidence that the eye images

49 significantly reduced littering rates or improved proper disposal compared to control

50 images or locations. In two of the studies (Ernest-Jones, Nettle \& Bateson, 2011; Bateson et

51 al., 2013), it was shown that the effect did not require the display of any explicit message

52 concerning littering. Participants presumably know that littering is perceived negatively; 
53 this and the general connection between being watched and the desire for a positive social

54 reputation (Oda et al., 2011) appear to be sufficient for the effect to work.

55 Whilst these results were encouraging, it is not practical to envisage displaying wall-

56 mounted watching eyes signs in every location where littering could occur. A more

57 promising strategy might be to transfer the watching eyes onto the potential litter itself, in

58 the form of images on packaging. The principle of placing anti-littering interventions onto

59 packaging is very well established. The limited experimental evidence suggests that such

60 interventions can have positive effects, but do not always do so: Wever et al. (2010), for

61 example, found that an obtrusive verbal message on cups reduced littering rates, but a less

62 obtrusive icon and message did not. However, to date no study has examined the effect of

63 placing images of watching eyes onto potential items of litter on littering rates.

64 In this paper, we present the results of two experiments designed to do this.

65 Several previous watching eyes studies have found interactions between the presence of 66 real human observers in the vicinity and the effectiveness of the artificial images of eyes 67 (Ernest-Jones, Nettle \& Bateson, 2011; Powell, Roberts \& Nettle, 2012; Ekström, 2012;

68 Bateson et al., 2013). The usual form such interactions take is that the eye images are more 69 effective (or only effective) when there are few or no real observers nearby (Ernest-Jones, 70 Nettle \& Bateson, 2011; Powell, Roberts \& Nettle, 2012; Ekström, 2012). This makes sense:

71 a real person is presumably a much stronger cue of social observation than an artificial 72 image. It thus seems unlikely that images of eyes should have any incremental effect on 73 behaviour if there are already real observers in the environment. Bateson et al. (2013)

74 found a different pattern of interactions, namely that eye images were more effective when 75 the environment was very crowded than when it was moderately crowded. The authors 76 suggested that this might be reconciled with other findings by assuming a non-monotonic

77 relationship between the number of people in a location and the social attention paid to any 78 particular individual.

79 If a real person is a more potent cue of social observation than a mere image, the presence 80 of real observers should do more than just moderate the effectiveness of artificial eye 81 images. It should also be a significant predictor of behaviour in its own right. Applied to 
82 littering, we should expect that the proximity of other people would be a negative predictor

83 of littering at least as strong as the presence of artificial eye images. Ernest-Jones et al.

84 (2011) found evidence consistent with this principle. People littered less when there were

85 more people in proximity, with the sharpest contrast being between people who were alone

86 and those who were in small groups with 1-3 others. This connects to the idea of "natural

87 surveillance' from the urban studies literature (Jacob, 1961): urban spaces generate the

88 fewest social problems when they are busy and individuals are not hidden from one

89 another. The impact of natural surveillance is not widely documented in the littering

90 literature: the largest observational study of littering (Schultz et al., 2011) concluded that

91 being in a social group or in proximity to others had no effect on littering probability. Thus,

92 the effect of natural surveillance on littering behaviour requires clarification.

93 We therefore sought to examine the effects of artificial eye images and the proximity of real

94 people on littering behaviour in a field setting. As in one of our previous studies (Bateson et

95 al., 2013), we used the classic approach of generating an experimental opportunity to litter

96 by presenting people with a leaflet they would be likely to wish to dispose of, and observing

97 what they did with it (Cialdini, Reno \& Kallgren, 1990; Keizer, Lindenberg \& Steg, 2008). In

98 our case, the leaflet was attached to people's bicycles while they were parked. Whereas

99 Bateson et al. (2013) manipulated the presence of wall-mounted signs with eye images, we

100 manipulated whether or not there were eye images on the leaflet itself.

\section{Experiment 1}

\section{Introduction}

103 In experiment 1, the experimental conditions consisted of a simple contrast between a

104 leaflet showing a prominent image of watching eyes (the eyes condition), and the same

105 leaflet with the eyes part obscured (the control condition). The leaflet made no mention of

106 littering, since our previous work suggested that explicit verbal messages about littering

107 were not necessary for the watching eyes effect on littering to occur. We also recorded the

108 number of people other than the observed participant in the immediate vicinity. We

109 predicted that the probability of littering would be lower in the eyes than the control

110 condition, and lower with other people in the vicinity than without. We also predicted an 
111 interaction between experimental condition and proximity of other people, such that the

112 effect of experimental condition would be stronger when there were no real observers than

113 when there were.

\section{Methods}

115 Ethics statement. Ethical approval was obtained from the Psychology subcommittee of the

116 Faculty of Medical Sciences ethics committee, Newcastle University, approval number

117 278945. As participants were observed in a public place, and were not individually

118 identified or approached during the course of the experiment, it was not required or

119 appropriate to obtain informed consent or conduct debriefing.

120 Study site and participants. Data collection took place at two bicycle racks outside buildings

121 on Newcastle University campus used by large numbers of students and staff. Neither of the

122 racks featured the large wall-mounted watching eyes posters directed at cycle thieves that

123 we have installed as part of previous research (Nettle, Nott \& Bateson, 2012; Bateson et al.,

124 2013). Both sites were artificially lit and had litter bins in the vicinity.

125 Experimental design. We generated a standardized opportunity to litter by making

126 informational leaflets with a message unrelated to littering ("Beware of bike thieves. Lock

127 your bike."), printed in black and white on A5 paper. In the centre of the leaflet was an image

128 of large pair of direct-gaze male eyes with the legend "Cycle thieves. We are watching you"

129 and the logos of the local police and university (figure 1). This image has been used on large

130 wall-mounted signs in anti-cycle theft campaigns at Newcastle University (Nettle, Nott $\mathcal{E}$

131 Bateson, 2012). The experimental leaflet was likely to have been credible, since the

132 university security service does run leaflet campaigns to encourage students to lock their

133 bicycles, and the watching eyes image we used on the leaflet carries official university

134 branding and is a familiar sight around campus.

135 In the control condition, the eyes of the watching eyes image were completely obscured by

136 an overlaid graphic of a bicycle lock. This was a relatively strong control, as the university

137 and police logos and the words "Cycle thieves. We are watching you" were still clearly 
138 visible. Thus, any effect of the semantic activation of officialdom or the police, or verbal

139 invocation of surveillance, would be equally present in the control and eyes conditions: the

140 only difference was the presence of the eyes image itself. Leaflets were folded and attached

141 to one end of the handle-bars of bicycles at the rack using an elastic band (figure 2). The

142 position was intended to make it difficult for the cyclist to leave with their bicycle without

143 first removing the leaflet.

144 Data recording. The behavioural decisions of cyclists returning to their bicycles were

145 unobtrusively recorded by an observer (Rebecca Robinson) situated at least 20 metres

146 away. As in our previous study (Bateson et al., 2013), the categories of behavioural decision

147 recorded were: left without removing the leaflet from its position; kept it on the person (e.g.

148 in a pocket or bag); placed it in the rubbish bin; put elsewhere in the vicinity (for example

149 onto another bicycle); or threw it onto the ground. In addition to the behavioural decision,

150 we recorded the participant's approximate age, sex, and the number of other people in the

151 immediate vicinity (a radius of approximately $6 \mathrm{~m}$ ) at the time the interaction with the

152 leaflet occurred. Data were obtained in 7 sessions of recording between $30^{\text {th }}$ January and

$15328^{\text {th }}$ February 2014 on weekdays during university teaching hours. All occurred in daylight,

154 with either fine weather or light rain. Only one condition (eyes or control) was run during a

155 session. Both conditions were run in both locations.

156 Data Analysis. For the purposes of statistical analysis, we assumed that each returning

157 cyclist constituted an independent unit of analysis. This assumption is reasonable in view of

158 the large numbers of people that use both of the study sites, the observation sessions being

159 held at differing times on different weekdays, and the asynchronous arrival of cyclists

160 during the sessions. We required a binary dependent variable of littering or no littering. We

161 classified throwing the leaflet on the ground as littering, and keeping the leaflet on person,

162 placing it in a rubbish bin, or placing it elsewhere in the environment as not littering. Cases

163 where the participant left without removing the leaflet from its position were excluded,

164 since we could not be sure that the participant had noticed the leaflet and hence could not

165 justifiably treat them as having decided not to litter. This classification scheme was identical

166 to that used in our previous study (Bateson et al., 2013), and its use was preplanned.

167 However, leaving the leaflet elsewhere in the environment (which was almost always on 
168 another bicycle) is ambiguous. It is not the overtly antisocial behaviour our study was

169 seeking to reduce, and it could be that the participant wants another cyclist to have the

170 information on the leaflet. However, it is a quick way of getting rid of the leaflet. We have

171 therefore repeated all the analyses with cases of leaving the leaflet elsewhere in the

172 environment excluded rather than treated as not littering, and the results are substantively

173 the same.

174 There was limited variation in age (98\% of participants judged to be under 25) and sex

175 ( $86 \%$ of participants judged to be male), and so effects of age and sex were not considered

176 further. The number of other people in the vicinity had a highly right-skewed distribution

177 with a mode of 0 (range $0-6$ ). We therefore dichotomized it into whether there was

178 someone else in the vicinity or not for the purposes of the analysis.

179 As our dependent variable was dichotomous, we modeled the data using a generalized

180 linear model with binomial error structure and a logit link function, using the 'glm' function

181 in R (R Core Development Team, 2013). The logit link is the default link function for a

182 binomial error structure, and has the advantage that its coefficients are interpretable as log

183 odds ratios. The independent variables were condition (eyes vs. control), someone else in

184 vicinity (true/false), and the condition by someone in vicinity interaction. The model was

185 repeated using a generalized linear mixed model with an additional random effect of site,

186 but the differences made by the addition of the random effect were trivial and so the results

187 of this model are not shown.

188 Results

189 The raw data from experiment 1 are downloadable as Supporting Information. There were a

190 total of 316 observations. The breakdown of behavioural decisions observed is shown in

191 table 1. Dichotomization of these into 'littered' and 'did not litter' produced 31 instances of

192 littering and 253 of not littering. Figure 3A shows the proportion of participants littering by

193 condition and whether there was someone else in the vicinity. The figure suggests a greater

194 probability of littering when there was no-one else in the vicinity than when there was

195 someone else, and in the control condition compared to the eyes condition, regardless of

196 whether there was someone else in the vicinity or not. This was borne out by the statistical 
197 model. The model fit the data substantially better than a null model (likelihood ratio test, $\chi^{2}{ }_{3}$

$198=25.17, \mathrm{p}<0.01)$. There were significant main effects of condition $(\mathrm{B}=-1.13$, s.e. $(\mathrm{B})=0.55$,

$199 \mathrm{z}=-2.05, \mathrm{p}=0.04)$ and presence of someone else in the vicinity $(\mathrm{B}=-1.38$, s.e. $(\mathrm{B})=0.47, \mathrm{z}=$

$200-2.92, \mathrm{p}<0.01)$, but the interaction between condition and presence of someone else was

201 not significant $(B=-0.62$, s.e. $(B)=0.96, z=-0.65, p=0.52)$.

202

203 Discussion

204 In line with our predictions, there were significant negative effects of the watching eyes 205 image and of there being other people in the vicinity on littering. Coefficients from logistic 206 regression can be interpreted as log odds ratios, and so the eyes condition coefficient of $207-1.13$ corresponds to an odds ratio of 0.32 for people to litter when the leaflet showed eyes 208 than when it did not. The 'someone else in the vicinity' coefficient of -1.38 corresponds to 209 an odds ratio of 0.25 for littering when someone else is in the vicinity compared to when 210 no-one was. These would be considered large effects (Cohen, 1988).

211 Contrary to our prediction, there was no evidence of an interaction between the presence of 212 other people in the vicinity and the experimental condition. The interaction we predicted, 213 based on previous findings (Ernest-Jones, Nettle \& Bateson, 2011; Powell, Roberts \& Nettle, 214 2012; Ekström, 2012), was that the effects of watching eyes image on the leaflet would be 215 larger when no real people were in the vicinity. In fact, the effect appeared uniform whether 216 there were others in the vicinity or not (see figure 3A). We were not able to establish 217 whether the different interaction effect found by Bateson et al. (2013), with the watching 218 eyes manipulation having a larger effect when the area was very crowded than when it was 219 moderately crowded, was present. That interaction was driven by a large eyes effect when 220 the number of other people in the vicinity exceeded six. There were many such instances in 221 the previous study, but none at all in the present one. This may reflect differences in time 222 and day of recording, and chance coincidence with busy university events.

223 The prevalence of littering we observed was substantially lower (10.9\%) than in our 224 previous study using the same method (Bateson et al., 2013; 23.2\% in the no-litter 225 conditions ). This was partly due to the large experimental effect we observed in the present 226 study; the two most directly comparable non-eyes conditions, the control condition of the 
227 present experiment and the no eyes, no litter condition of Bateson et al. (2013), produced

228 fairly similar littering rates (16.8\% and $20.1 \%$ respectively).

\section{Experiment 2}

\section{Introduction}

231 The results of experiment 1 suggested that placing an image of watching eyes on a piece of 232 potential litter did influence people's littering decisions, making them less likely to do so.

233 We felt it important to replicate this result. Moreover, the watching eyes image on the 234 experimental leaflet was very large, occupying a substantial portion of the leaflet's area. It 235 would not be feasible to persuade manufacturers to devote such a large portion of their 236 packaging to an anti-littering intervention. In experiment 2, as a first step towards a more 237 translatable intervention, we experimented with reducing the size of the watching eyes 238 image, to examine the impact on its effectiveness. Experiment 2 therefore repeated the 239 procedure of experiment 1, but adding a third condition in which the watching eyes 240 stimulus was reduced in size. In this 'small eyes' condition, both the width and height of the 241 stimulus were reduced to one third of their previous values, meaning that the total area was 242 reduced by around 89\% (see figure 1). As before, we predicted that there would be a main 243 effect of eyes (lower probability of littering in either eyes condition compared to control), a 244 main effect of people in the vicinity (lower probability of littering when other people were 245 in the vicinity), and an interaction between condition and other people in the vicinity (eyes 246 conditions having a greater effect when there were few other people in the vicinity). We 247 were particularly interested in whether any watching eyes effect would be weaker for the 248 small eyes leaflet compared the large eyes.

\section{Methods}

250 Ethics statement. Ethical approval was obtained from the Psychology subcommittee of the 251 Faculty of Medical Sciences ethics committee, Newcastle University, approval number 252753137 , on the same basis as for experiment 1. 
253 Study sites, participants and data recording. Data collection was carried out on rain-free days 254 between December $1^{\text {st }} 2014$ and January $30^{\text {th }} 2015$ using the same protocol and coding 255 scheme as experiment 1 , although in experiment 2 the leaflets were reproduced in colour 256 rather than black and white. A third site within the campus was added to the two used in 257 experiment 1. Data were collected by either Tim Abayomi-Cole, Josh Greenless or Abby 258 O'Connor. Pilot sessions were conducted with all three researchers present to establish 259 uniform scoring criteria. The control and small eyes conditions were run at all three sites, 260 and the large eyes condition at two of the three (the final site/condition combination was 261 omitted in error). Due to the short day length during December and early January, the sun 262 had set before the end of one session in each condition $8 \%$ of the total number of 263 observations were from after sunset. However, all study sites were artificially lit.

264 Data analysis. As in experiment 1, there was limited variation in participant age ( $92 \%$ 265 judged to be under 25) and sex (77\% male), and so age and sex are not considered further. 266 Number of other people in the vicinity again showed a right-skewed distribution with a 267 mode of 0 (range 0-6) and was therefore dichotomized into someone else in vicinity versus 268 no one else in vicinity, as in experiment 1 . The statistical model was the same as that for 269 experiment 1 save for the extra coefficients due to the extra experimental condition. As in 270 the previous study, repeating the model with a random effect of site produced only trivial 271 differences and the results of that model are not shown. To compare the results with those 272 of experiment 1 , we created a meta-analytic plot of the main effects of both studies using the 273 'metafor' package.

\section{Results}

275 The raw data from experiment 2 are downloadable as Supporting Information. We made a 276 total of 396 observations. The breakdown by behavioural decision is shown in table 2 .

277 Dichotomization of the behavioural decision produced 56 instances of littering and 257 of 278 not littering. Figure 3B shows the probability of littering by experimental condition and 279 presence of someone else in the vicinity. The figure suggests that both eyes conditions 280 substantially reduced the probability of littering compared to the control condition, but only 281 when there was no-one else in the vicinity. The statistical model confirms this. The model fit 
282 the data substantially better than a null model (likelihood ratio test, $\chi^{2}{ }_{5}=32.12, \mathrm{p}<0.01$ ).

283 There was a significant main effect of presence of someone else in the vicinity $(B=-3.12$, s.e.

$284(\mathrm{~B})=1.05, \mathrm{z}=-2.98, \mathrm{p}<0.01)$. The effect of the large eyes condition relative to control was

285 significant $(\mathrm{B}=-1.07$, s.e. $(\mathrm{B})=0.47, \mathrm{z}=-2.28, \mathrm{p}=0.02)$, as was the effect of the small eyes

286 condition relative to control ( $\mathrm{B}=-1.51$, s.e. $(\mathrm{B})=0.55, \mathrm{z}=-2.78, \mathrm{p}<0.01)$. There were also

287 significant interactions between the large eye condition and someone else in the vicinity (B

$288=3.40$, s.e. $(\mathrm{B})=1.17, \mathrm{z}=2.92, \mathrm{p}<0.01)$ and the small eye condition and someone else in the

289 vicinity $(B=2.57$, s.e. $(B)=1.23, z=2.10, p<0.01)$. These interactions were driven by the

290 fact that the probability of littering was lower for both eyes conditions than control when

291 no-one else was in the vicinity (coefficients of -1.07 for large eyes and -1.51 for small eyes),

292 but actually higher than the control conditions when there was someone else in the vicinity

293 (coefficients of 2.33 for large eyes and 1.06 for small eyes).

294 Figure 4 shows a meta-analytic plot of the main effects of experiments 1 and 2 for both the 295 experimental conditions, and the impact of there being someone else in the vicinity. As the

296 figure shows, the effect sizes from the two watching eyes conditions in experiment 2 are 297 similar to one another, and similar to the single effect size from experiment 1: odds ratios of 298 the order of 0.3 for littering when the leaflet has watching eyes compared to control. Figure 2994 also shows the effect sizes for the presence of someone else in the vicinity. These effects 300 were of similar magnitude to those of the watching eyes manipulation, and their confidence 301 intervals for experiments 1 and 2 overlapped.

\section{Discussion}

303 The pattern of behavioural decisions observed was similar to that seen in experiment 1 , and 304 in our previous study (Bateson et al., 2013), with most participants keeping the leaflet on 305 their person, and a minority throwing them on the ground. The overall rate of littering in 306 experiment $2(17.9 \%)$ was intermediate between that of the present experiment 1 and that 307 of Bateson et al. (2013). Experiment 2 replicated the main effects of experiment 1: littering 308 was significantly less frequent when there was someone else in the vicinity than when there 309 was no-one, and significantly less frequent in the eyes than the control conditions. The sizes 310 of these effects were of similar magnitude as those observed in experiment 1 (see figure 4). 
311 There was no indication at all that making the watching eyes image much smaller reduced

312 its effectiveness: the effect size for small eyes condition compared to control was

313 comparable to that for large eyes versus control.

314 Whilst the main effects were similar between experiments 1 and 2, the interaction effects 315 were not. In experiment 2, as predicted and in contrast to experiment 1, the watching eyes 316 manipulation was effective in reducing littering only when there were no real observers in 317 the vicinity. This was in keeping with previous research (Ernest-Jones, Nettle \& Bateson, 318 2011; Powell, Roberts \& Nettle, 2012; Ekström, 2012). However, the nature of the 319 interaction effect was subtly different from those studies. For Ernest-Jones et al. (2011) and 320 Powell et al. (2012), the watching eyes effect was attenuated when there were many real 321 observers in the vicinity, but not reversed. Here, we observed a stronger crossover 322 interaction: littering was actually more likely in the eyes than control conditions when there 323 were observers in the vicinity (see figure 3B). This crossover was not predicted and the 324 reasons for it are not clear. However, it was not sufficient to abolish the (negative) main 325 effects of eyes on littering: littering was still less likely to occur overall in the eyes than 326 control conditions. We were again unable to test for the pattern found in Bateson et al. 327 (2013) where the watching eyes effect became stronger in very crowded locations, since we 328 had no instances of more than six people in the vicinity.

\section{General Discussion}

330 In two separate experiments, we found that that the presence on a leaflet of an image of 331 watching eyes substantially reduced the probability that the leaflet would be littered. The 332 effects were large, with the eyes image reducing the odds of littering by around two thirds 333 compared to a closely-matched control leaflet given out in the same locations. These results 334 are consistent with body of other findings using various paradigms to show that displaying 335 images of watching eyes can often increase prosocial behaviour (Haley \& Fessler, 2005;

336 Bateson, Nettle \& Roberts, 2006; Burnham \& Hare, 2007; Keller \& Pfattheicher, 2011; Oda et 337 al., 2011; Nettle et al., 2012; Powell, Roberts \& Nettle, 2012; Baillon, Selim \& van Dolder, 338 2013; Sparks \& Barclay, 2013), and with previous studies on watching eyes and littering 339 more specifically (Ernest-Jones, Nettle \& Bateson, 2011; Francey \& Bergmuller, 2012; 
340 Bateson et al., 2013). One of the experiments, though not the other, confirmed the pattern

341 seen in several previous studies where the effectiveness of the eye images was moderated

342 by whether or not there were any real people in the vicinity (Ernest-Jones, Nettle \& Bateson,

343 2011; Powell, Roberts \& Nettle, 2012; Ekström, 2012).

344 In both experiments, we found a main effect of the presence of real observers in the vicinity.

345 People were much less likely to litter when there were other people around them,

346 concurring with one of our previous studies (Ernest-Jones, Nettle \& Bateson, 2011). This

347 effect was at least as strong as the experimental watching eyes image effect. In a sense this

348 is a reassuring finding: it would after all be very strange if people's behaviour responded to

349 artificial cues of social observation, but was impervious to real cues. It highlights the

350 important of 'natural surveillance' - people using public spaces and not being hidden from

351 one another - in the self-regulation of urban spaces (Jacob, 1961). A previous large

352 observational study of littering (Schultz et al., 2011) did not detect any influence of the

353 number of people in the vicinity. Had there been effects of anything like the size found in

354 our experiments, that study would have had the statistical power to detect them. Thus, this

355 discrepancy requires further investigation.

356 The experiments presented here have a number of scientific and practical limitations. On

357 the scientific side, our design does not allow us to discriminate between, on the one hand,

358 only eye images reducing littering and, on the other, any image invoking people being

359 equally effective. Such controls have been investigated elsewhere, and the results suggest a

360 specific effect of eyes rather than just the invocation of people (Baillon, Selim \& van Dolder,

361 2013). We also investigated only a single watching eyes image: a stern pair of male eyes we

362 have used in previous research on the same campus, and hence whose use would not arouse

363 suspicion. We have not shown whether the same effect could be achieved using other, less

364 intimidating eye stimuli. However, we note that some watching eyes studies on behaviours

365 other than littering have used stimuli including friendlier and more positive eye images, and

366 still found significant eyes effects (Nettle et al., 2012; Powell, Roberts \& Nettle, 2012; e.g.

367 Baillon, Selim \& van Dolder, 2013). The results of the two experiments also differed

368 somewhat. Since the protocol was varied in a number of minor ways beyond the addition of

369 the extra condition (for example, printing in colour rather than black-and-white in 
370 experiment 2), the differences cannot be definitively explained without further

371 experimentation. Finally, although our field experimental approach minimizes demand

372 characteristics and produces data with high ecological validity, it does not provide any

373 insight into the psychological processes underlying the observed effects. Other kinds of

374 studies are required to shed light on these issues (see e.g. Oda et al., 2011; Pfattheicher $\mathcal{E}$

375 Keller, 2015).

376

377 The eye images we used, as well as being intimidating, were very large and prominent, 378 much larger and more prominent than it would be feasible to persuade manufacturers to 379 include on packaging. When we reduced their area in experiment 2, its effectiveness was 380 completely undiminished. However, even the small eyes image remained very central to the 381 leaflet (especially when folded on the bicycle handlebars), and the leaflet had little else in 382 terms of visual elements. For practical usability, it would be important to establish that the 383 effect could still be found using an eye image that was even smaller and less threatening in 384 in a design crowded with other visual elements. Perceptual research shows that directly385 gazing faces capture processing priority in crowded visual scenes (Rothkirch et al., 2015). 386 Furthermore, the stimuli used in some previous watching eyes studies have been extremely 387 subtle (Haley $\&$ Fessler, 2005; Rigdon et al., 2009; Powell, Roberts $\&$ Nettle, 2012). Thus, it is 388 plausible that a watching eyes image on packaging could be effective whilst being small and 389 unobtrusive enough to be acceptable to manufacturers. However, further experimentation is 390 required to establish unambiguously that this is the case.

391 Both the results presented here and those of our previous studies (Ernest-Jones, Nettle $\mathcal{E}$ 392 Bateson, 2011; Bateson et al., 2013) support the view that it is not necessary to accompany 393 the eye images with explicit verbal messages about littering. People know that littering is 394 antisocial, and there appears to be a fundamental connection between observability and 395 reluctance to be antisocial (Kraft-Todd et al., 2015). This is potentially very important: 396 incorporating an anti-littering design element in packaging might be much more widely 397 acceptable to manufacturers if it did not have to be obvious that this was its function. If it 398 could simply be the face of someone endorsing or enjoying the product, then it is something 399 that manufacturers might already incorporate anyway, or might need little persuasion to do 400 so. We have not, however, tested the effectiveness of our watching eyes type intervention 
401 against a package element explicitly discouraging littering or encouraging proper disposal. 402 Explicit messages have been shown to be effective in reducing littering in general (Huffman 403 et al., 1995), and there is a limited amount of experimental evidence that they can be 404 effective when placed on the potential litter items (Wever et al., 2010). Direct assessment of 405 the relative effectiveness of watching eyes images and explicit litter-related messages on 406 packaging, and the potential for combining these two components to maximize 407 effectiveness, would be useful avenues for future research.

408 In view of litter's negative aesthetic and environmental impacts, the tendency for litter to 409 beget more litter, and the tendency of litter to promote other forms of disorder, the potential 410 societal benefits from cheap interventions that reduce littering by even a small amount are 411 very large. We have presented initial evidence here that placing images of watching eyes 412 onto packaging could reduce littering and promote correct disposal. We hope that 413 designers, manufacturers and regulators might be able to develop, refine and implement 414 this principle in the future. 
415 References

416 Baillon A., Selim A., van Dolder D. 2013. On the social nature of eyes: The effect of social cues 417 in interaction and individual choice tasks. Evolution and Human Behavior 34:146-154.

418 Bateson M., Callow L., Holmes JR., Redmond Roche ML., Nettle D. 2013. Do images of 419 "watching eyes" induce behaviour that is more pro-social or more normative? A field $420 \quad$ experiment on littering. PloS one 8:e82055.

421 Bateson M., Nettle D., Roberts G. 2006. Cues of being watched enhance cooperation in a real$422 \quad$ world setting. Biology Letters 2:412-414.

423 Burnham TC., Hare B. 2007. Engineering human cooperation. Does involuntary neural 424 activation increase public goods contributions? Human Nature 18:88-108.

425 Cialdini RB., Reno RR., Kallgren CA. 1990. A focus theory of normative conduct: Recycling 426 the concept of norms to reduce littering in public places. Journal of Personality and 427 Social Psychology 58:1015-26.

428 Cohen J. 1988. Statistical Power Analysis for the Behavioral Sciences. Hillsdale, NJ: Lawrence $429 \quad$ Erlbaum Associates.

430 Ekström M. 2012. Do watching eyes affect charitable giving? Evidence from a field 431 experiment. Experimental Economics 15:530-46.

432 Ernest-Jones M., Nettle D., Bateson M. 2011. Effects of eye images on everyday cooperative 433 behavior: a field experiment. Evolution and Human Behavior 32:172-178.

434 Francey D., Bergmuller R. 2012. Images of eyes enhance investments in a real-life public 435 good. PloS ONE 7:e37397.

436 Haley KJ., Fessler DMT. 2005. Nobody's watching? Subtle cues affect generosity in an 437 anonymous economic game. Evolution and Human Behavior 26:245-256.

438 Huffman KT., Grossnickle WF., Cope JG., Huffman KP. 1995. Litter reduction: A review and 439 integration of the literature. Environment and Behavior 27:153-183.

440 Jacob J. 1961. The Death and Life of Great American Cities. New York: Random House.

441 Keizer K., Lindenberg S., Steg L. 2008. The spreading of disorder. Science:1681-1685.

442 Keller J., Pfattheicher S. 2011. Vigilant self-regulation, cues of being watched and 443 cooperativeness. European Journal of Personality 25:363-72.

444 Kraft-Todd G., Yoeli E., Bhanot S., Rand D. 2015. Promoting cooperation in the field. Current $445 \quad$ Opinion in Behavioral Sciences 3:96-101.

446 Kraus RM., Freedman JL., Whitcup M. 1978. Field and laboratory studies of littering. Journal 447 of Experimental Social Psychology 14:109-22. 
448 Nettle D., Harper Z., Kidson A., Stone R., Penton-Voak IS., Bateson M. 2012. The watching 449 eyes effect in the Dictator Game: it's not how much you give, it's being seen to give 450 something. Evolution and Human Behavior 34:35-40.

451 Nettle D., Nott K., Bateson M. 2012. “Cycle thieves, we are watching you”: impact of a simple 452 signage intervention against bicycle theft. PloS one 7:e51738.

453 Oda R., Niwa Y., Honma A., Hiraishi K. 2011. An eye-like painting enhances the expectation of 454 a good reputation. Evolution and Human Behavior 32:166-171.

455 Pfattheicher S., Keller J. 2015. The watching eyes phenomenon: The role of a sense of being 456 seen and public self-awareness. European Journal of Social Psychology 45:560-66.

457 Powell KL., Roberts G., Nettle D. 2012. Eye Images Increase Charitable Donations: Evidence 458 From an Opportunistic Field Experiment in a Supermarket. Ethology 118:1096-1101.

459 R Core Development Team. 2013. R: A Language and Environment for Statistical Computing.

460 Rigdon M., Ishii K., Watabe M., Kitayama S. 2009. Minimal social cues in the dictator game. $461 \quad$ Journal of Economic Psychology 30:358-367.

462 Rothkirch M., Madipakkam AR., Rehn E., Sterzer P. 2015. Making eye contact without 463 awareness. Cognition 143:108-114.

464 Schultz PW., Bator RJ., Large LB., Bruni CM., Tabanico JJ. 2011. Littering in Context: Personal 465 and Environmental Predictors of Littering Behavior. Environment and Behavior 45:3546659.

467 Sparks A., Barclay P. 2013. Eye images increase generosity, but not for long: the limited effect 468 of a false cue. Evolution and Human Behavior 34:317-322.

Weaver R. 2015. Littering in context(s): Using a quasi-natural experiment to explore 470 geographic influences on antisocial behavior. Applied Geography 57:142-153.

471 Wever R., van Onselen L., Silvester S., Boks C. 2010. Influence of packaging design on 472 littering and waste behaviour. Packaging and Technology and Science 23:253-266. 
473 Table 1. Summary of behavioural decisions (number and \% of observations within 474 condition) observed in experiment 1.

$\begin{array}{lllll}\begin{array}{l}\text { Behavioural Decision } \\ \text { Left without removing }\end{array} & \begin{array}{l}\text { Overall } \\ 32(10.1 \%)\end{array} & \begin{array}{l}\text { Control } \\ 10(6.8 \%)\end{array} & \begin{array}{l}\text { Eyes } \\ 22(13.0 \%)\end{array} & \begin{array}{l}\text { Classification } \\ \text { Excluded }\end{array} \\ \begin{array}{l}\text { leaflet } \\ \text { Kept on person }\end{array} & 188(59.5 \%) & 84(57.1 \%) & 104(61.5 \%) & \text { Did not litter } \\ \text { Put in bin } & 0(0 \%) & 0(0 \%) & 0(0 \%) & \text { Did not litter } \\ \text { Put elsewhere } & 65(20.6 \%) & 30(20.4 \%) & 35(20.7 \%) & \text { Did not litter } \\ \text { Threw on ground } & 31(9.8 \%) & 23(15.6 \%) & 8(4.7 \%) & \text { Littered }\end{array}$


475 Table 2. Summary of behavioural decisions (number and \% of observations within 476 condition) observed in experiment 2.

$\begin{array}{llllll}\begin{array}{l}\text { Behavioural Decision } \\ \text { Left without }\end{array} & \begin{array}{l}\text { Overall } \\ 83(21.0 \%)\end{array} & \begin{array}{l}\text { Control } \\ 53(35.3 \%)\end{array} & \begin{array}{l}\text { Large eyes } \\ 11(10.1 \%)\end{array} & \begin{array}{l}\text { Small eyes } \\ 19\end{array} & \begin{array}{l}\text { Classification } \\ \text { Excluded }\end{array} \\ \begin{array}{l}\text { removing leaflet } \\ \text { Kept on person }\end{array} & 205(51.8 \%) & 63(42.0 \%) & 58(53.7 \%) & 84 & \text { Did not litter } \\ & & & & (60.9 \%) & \\ \begin{array}{l}\text { Put in bin } \\ \text { Put elsewhere }\end{array} & 11(2.8 \%) & 0(0 \%) & 5(4.6 \%) & 6(4.3 \%) & \text { Did not litter } \\ & 41(10.4 \%) & 9(6.0 \%) & 14(13.0 \%) & 18 & \text { Did not litter } \\ \text { Threw on ground } & 56(14.1 \%) & 25(16.7 \%) & 20(18.5 \%) & 11(8.0 \%) & \text { Littered }\end{array}$


A

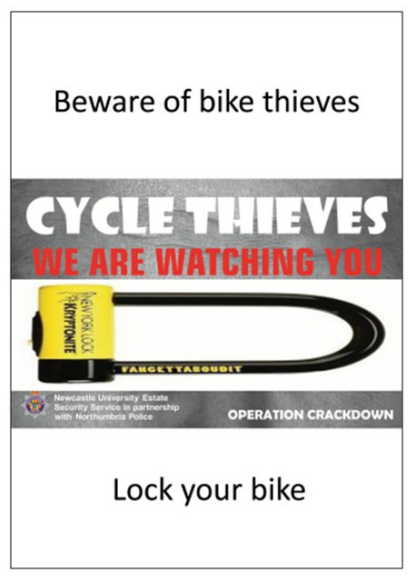

B

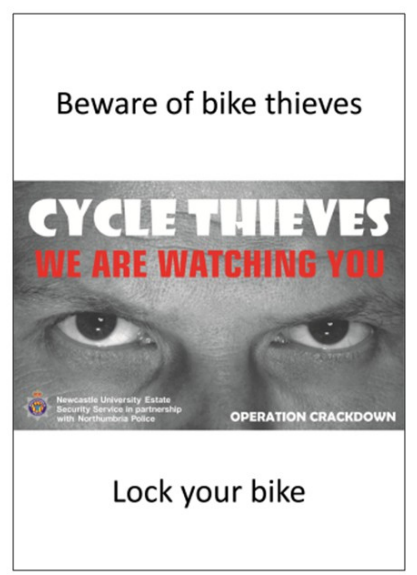

C

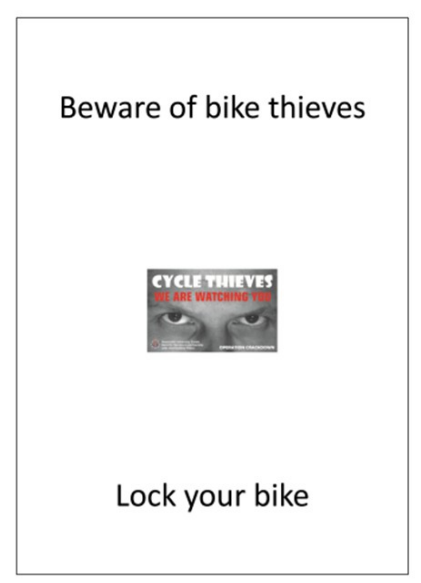

477 Figure 1. Leaflets used in the experiments. Note that the leaflets were printed in black and 478 white in experiment 1 and colour in experiment 2. A: The control condition of both 479 experiments. B: The eyes condition of experiment 1 / large eyes condition of experiment 2. 480 C: The small eyes condition used in experiment 2 only. 


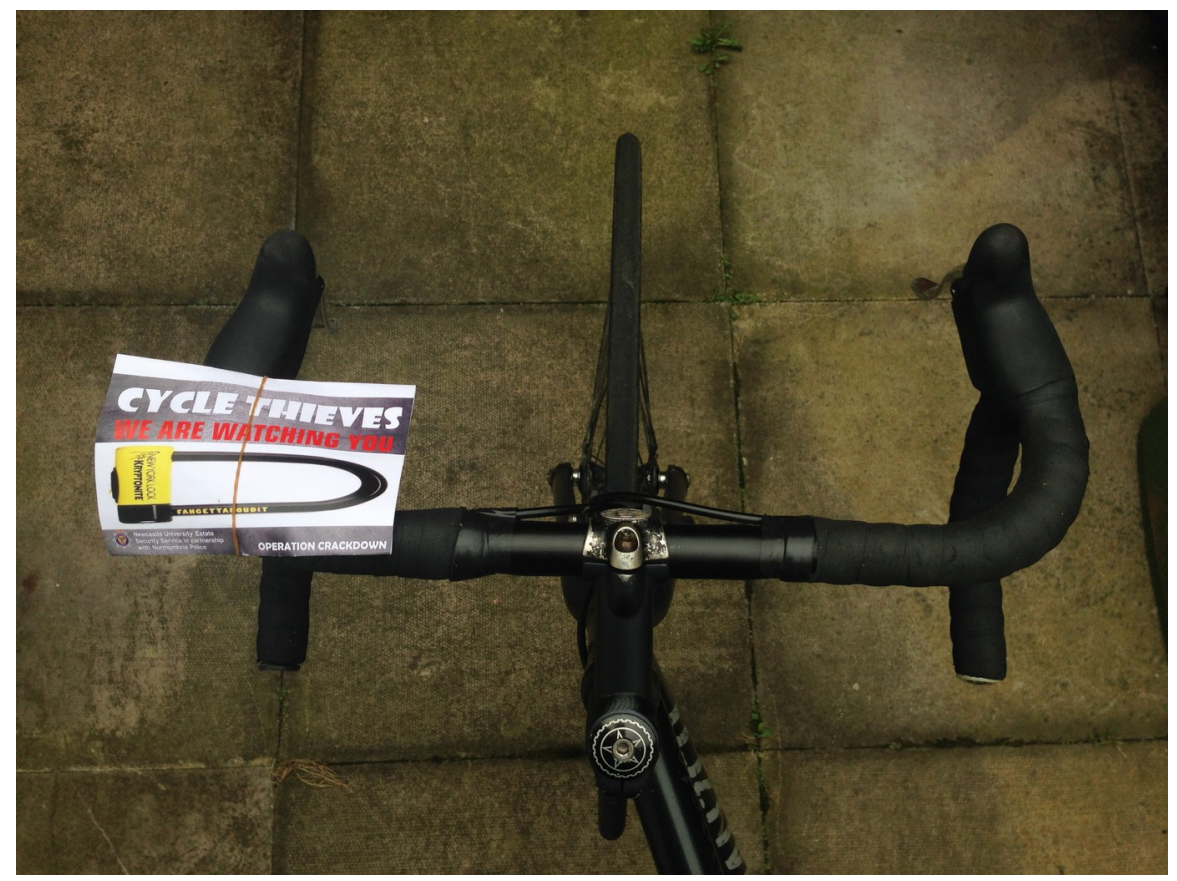

481 Figure 2. Illustration of the position of a leaflet on bicycle handlebars. 

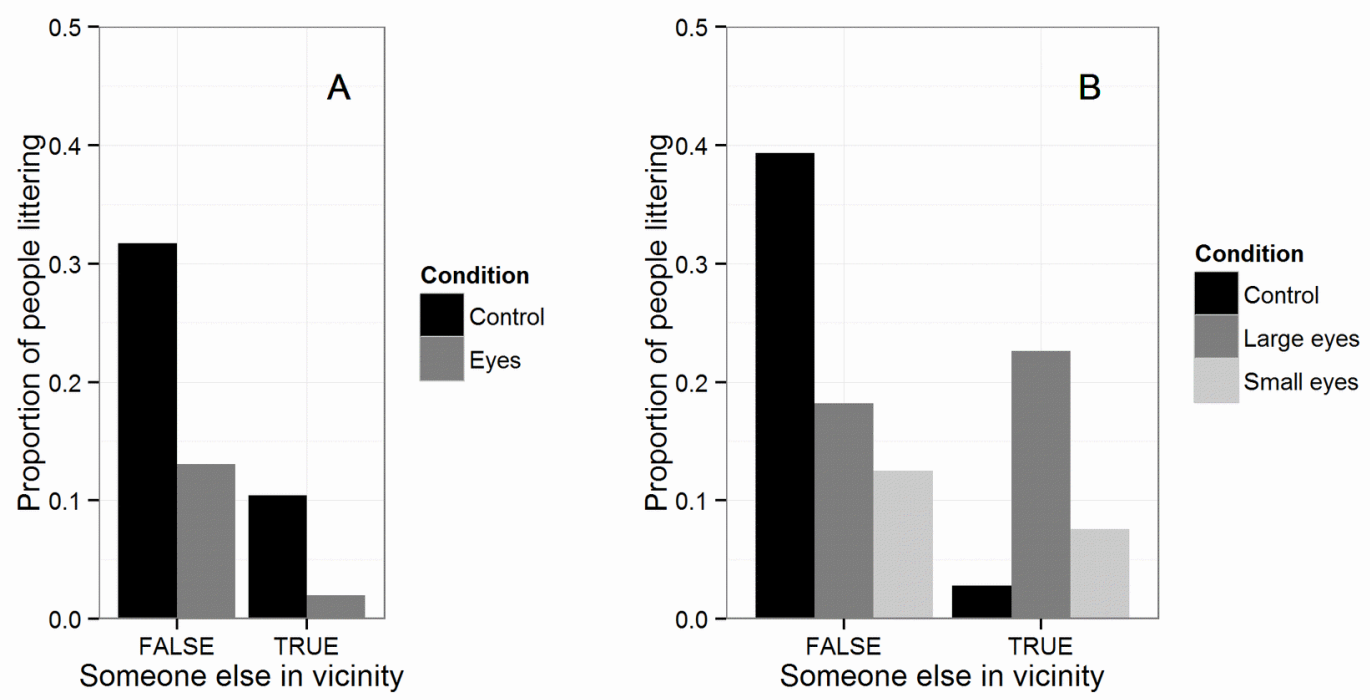

482 Figure 3. Probability of littering by experimental condition and presence of someone else in 483 the vicinity. A: Experiment 1. B: Experiment 2. 


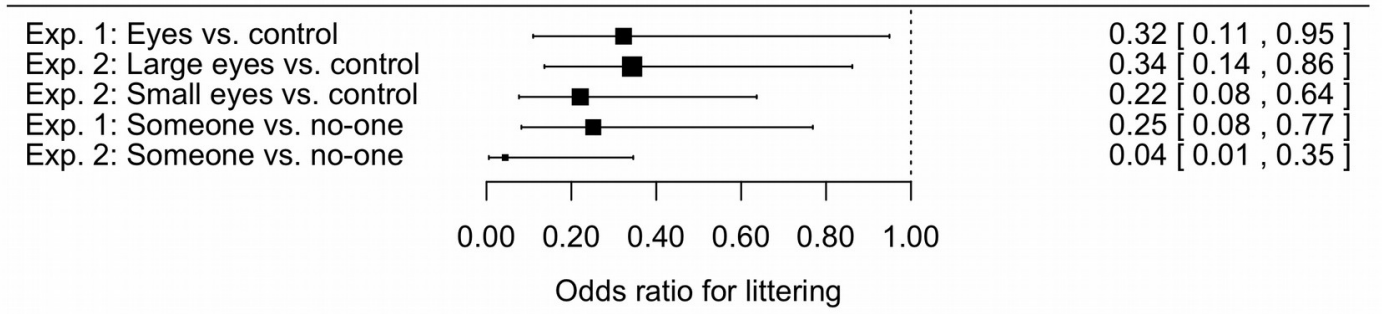

484 Figure 4. Meta-analytic forest plot of the main effects observed in experiments 1 and 2.

485 Parameter estimates from the statistical models and their standard errors have been

486 transformed into odds ratios and their $95 \%$ confidence intervals. 